\title{
MEASUREMENT OF FLAT SLAB DEFORMATIONS BY THE MULTI-IMAGE PHOTOGRAMMETRY METHOD
}

\author{
Marián MARČIŠ1* ${ }^{*}$ Marek FRAŠTIA ${ }^{1}$, Tomáš AUGUSTíN²
}

\begin{abstract}
The use of photogrammetry during load tests of building components is a common practise all over the world. It is very effective thanks to its contactless approach, 3D measurement, fast data collection, and partial or full automation of image processing; it can deliver very accurate results. Multi-image convergent photogrammetry supported by artificial coded targets is the most accurate photogrammetric method when the targets are detected in an image with a higher degree of accuracy than a 0.1 pixel. It is possible to achieve an accuracy of $0.03 \mathrm{~mm}$ for all the points measured on the object observed if the camera is close enough to the object, and the positions of the camera and the number of shots are precisely planned. This contribution deals with the design of a special hanging frame for a DSLR camera used during the photogrammetric measurement of the deformation of flat concrete slab. The results of the photogrammetric measurements are compared to the results from traditional contact measurement techniques during load tests.
\end{abstract}

\section{Address}

1 Department of Surveying, Faculty of Civil Engineering, Slovak University of Technology, Bratislava, Slovakia

2 Department of Concrete Structures and Bridges, Faculty of Civil Engineering, Slovak University of Technology, Bratislava, Slovakia

* Corresponding author: marian.marcis@stuba.sk

\section{Key words}

- Photogrammetry,

- Deformation measurement

- Flat slab,

- Strain,

- Load test.

\section{INTRODUCTION}

Load test experiments of building components are mostly monitored using traditional linear variable differential transformers (LVDT), strain gauges and deformeters. Although this equipment delivers a high degree of accuracy of the changes in length measured, it is also very limiting as it offers only $1 \mathrm{D}$ measurements between points and thus might not be effective in measuring larger objects in sufficient detail. Digital photogrammetry can handle all of these aspects, including the high density of measurements and a high degree of accuracy of the 3D coordinates of the points observed. However, to obtain results that require a high degree of precision, it is very important to implement the proper combination of a camera system, network configuration and processing software with its overall settings.

The aim of this paper is to introduce the capabilities of digital photogrammetry to the professionals in the field of civil engineering that still use the traditional methods of 1D measurements in structural monitoring, despite many publications that have confirmed the high accuracy and effectivity of photogrammetry in such applications. Also we want to present a cheap and universal solution of camera mounting for photogrammetric purposes when the laboratory conditions don't allow ideal camera positions using a tripod or a ladder.

\section{PREVIOUS WORK}

Digital photogrammetry is widely used in civil engineering, most commonly either as a method for the documentation of the current state of an object or to track its movements and deformations (Urban et al., 2015; Šedina et al., 2016). The rising use of computer vision techniques such as Structure from Motion (SfM) enables the automatical generation of 3D models from images based on a surface texture 
(Lucieer et al., 2013). Nevertheless, multi-image convergent photogrammetry is still the most accurate digital photogrammetry method (Šedina \& Pavelka, 2016). Its main advantages are the considerable freedom of camera positions and relative orientations. However, to obtain reliable results, the camera positions should be located at regular intervals around the object, and the circular or coded targets should be large enough and clearly visible. With the use of circular targets, the accuracy measurements of image coordinates in tenths and hundredths of a pixel can be achieved (Luhmann et al., 2006). Depending on the configuration of the specific system (camera type, object size, intersection angle and number of rays per point), this high accuracy of image coordinates can be translated into a high attainable accuracy in the object's coordinate system - in tenths and hundredths of millimetres. Considering the previous facts, the non-contact character and high accuracy of digital photogrammetry can lead to a broad field of applications dealing with static or dynamic deformation measurements.

The state-of-the-art of industrial photogrammetry is well described by Luhmann (2010), but there were many studies performed in the last 10 years confirming the high achievable accuracy and effectivity of photogrammetry in structural monitoring applications.

Fraser \& Riedel (2000), used an on-line configuration of three $\mathrm{CCD}$ cameras to measure targets on seven super-hot $9 \mathrm{~m}$ long steel beams with dimensional tolerance of close to $1 \mathrm{~mm}$ (RMS 1-sigma).

Parian et al. (2008) designed an optimal close-range photogrammetric network by heuristic simulation for the Primary and Secondary Reflectors of the European Space Agency's Planck telescope with a mean relative precision better than 1: 1,000,000 and 1: 400,000 (several micrometres in the object's space).

Lee et al. (2008) followed a 2D approach (time base-line method) to measure 1500 targets on a $6 \mathrm{~m}$ T-beam under a shear test. The degree of precision attained was $0.06 \mathrm{~mm}$, and the experiment was focused on almost real-time crack detection.

Detchev et al. (2011) used a pre-calibrated seven camera system on top of a $3 \mathrm{~m}$ concrete beam under a deflection loading test. The photogrammetric measurements revealed differences of a max 0.4 $\mathrm{mm}$ compared to 1D laser transducers.

The space- and time-resolved crack detection in concrete structures was published by Koschitzki et al. (2011). They combined the photogrammetric techniques with an acoustic emission analysis and an online system allowed to track the growth of the cracks and to stop the experiment before a critical bearing status was reached.

Chounta and Ioannidis (2012) used synchronised stereo camcorders to determine the three-dimensional displacements of 34 targets signalised on a reinforced concrete beam. The targets covered an area of approximately $0.7 \mathrm{~m} \times 1.0 \mathrm{~m}$. The estimated accuracy of the XYZ target coordinates was $0.5-1 \mathrm{~mm}$.

Valença, J. et al. (2012) tested the digital photogrammetry in structural monitoring and compared the photogrammetric results to the results obtained with LVDTs. The processing of 6 images from a distance of 6-7 m during a steel connection test produced 3D points with precision of $0.03 \mathrm{~mm}$.

Digital photogrammetry delivers highly accurate results from the tracking of aerodynamic surfaces and aerospace models at NASA Langley Research Center (Shortis et al., 2016). A $0.1 \mathrm{~mm}$ degree of precision of the XYZ target coordinates was achieved using a Canon Powershot A80 digital camera with a network of 30 exposures and 40 targets.

Despite the amount of studies that prove the usability and advantages of digital photogrammetry in this area, it is still not the main method used for the monitoring of laboratory load tests in the Slovak Republic environment.

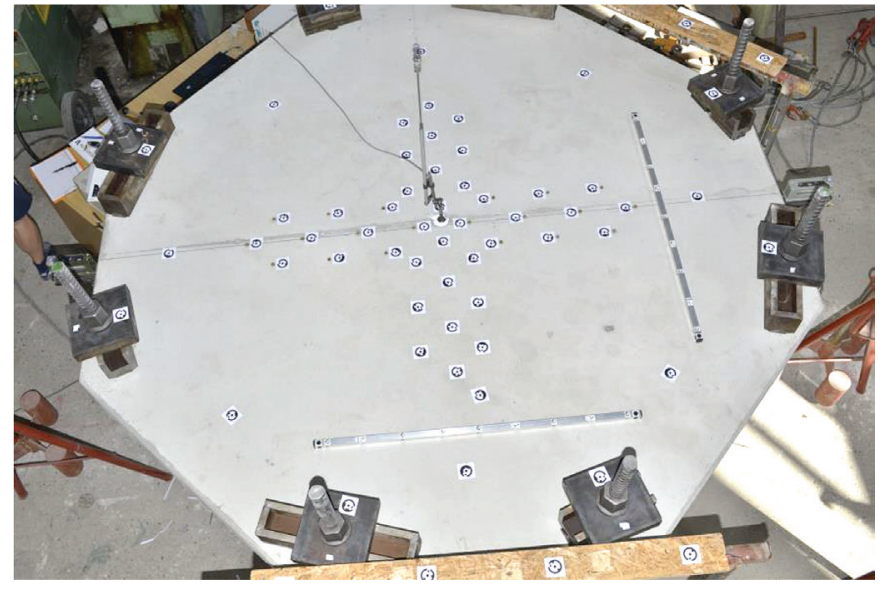

Fig. 1 Monitored specimen with photogrammetric targets and scale bars.

\section{SUBJECT OF MEASUREMENT}

The subject of the photogrammetric measurements presented in this paper was a load-test of a reinforced flat slab (Fig. 1). The original building component was represented by an octagonal segment of a flat slab with $5400 \mathrm{~mm} \times 5400 \mathrm{~mm}$ spans, while the size of the specimen actually tested was $2400 \mathrm{~mm}$ x $2400 \mathrm{~mm}$. The parameters of the flat slab were the following: thickness: $250 \mathrm{~mm}$; the upper reinforcement: $\phi 20 / 100 \mathrm{~mm}$ with $c_{\text {nom }} 30 \mathrm{~mm}(d=200 \mathrm{~mm})$; reinforcement ratio: $\rho=0,016$; the lower reinforcement: $\phi 10 / 200 \mathrm{~mm}$ with $c_{\text {nom }} 30$ $\mathrm{mm}$; the dimensions of the column: $200 \times 200 \mathrm{~mm}$; and the concrete's compressive strength: $33.41 \mathrm{MPa}$. During the experimental work, the specimen was loaded with a hydraulic jack situated under the column. The specimen was tied to the strong floor of a laboratory with 8 steel rods. The loading configuration was based on the previous work of colleagues from the Department of Concrete Structures and Bridges of the Faculty of Civil Engineering, Slovak University of Technology in Bratislava (DCSB) (Majtánová et al., 2016).

\section{METHODOLOGY}

The previous photogrammetric measurements in cooperation with DCSB were done using a ladder, which caused time and position limitations because of obstacles on the floor around the flat slab. These limitations led to a poor network configuration (small number of camera positions, intersection angles) and a maximum degree of accuracy of $0.1 \mathrm{~mm}$ in the 3D object's coordinate system was achieved (based on the comparison of results with the deformeter and LVDTs measurement). Therefore, a special hanging system for the camera mount was developed to obtain a better network of the camera positions around the specimen measured and more precise results.

\subsection{Hanging system for the camera mount}

The camera's mounting construction was made from Dural because of its stiffness and low weight. It was attached to a crane $6 \mathrm{~m}$ above the specimens' surface (Fig. 2).

The construction enables rotating the arm with a mounted camera around the object and take a theoretically unlimited number of images with ideal angles of the rays' intersection at the photogrammetric points $\left(60^{\circ}\right.$ to $\left.90^{\circ}\right)$. It is designed in such a way that it can be easily modifiable for various camera heights and rotation radiuses. The stability of the 

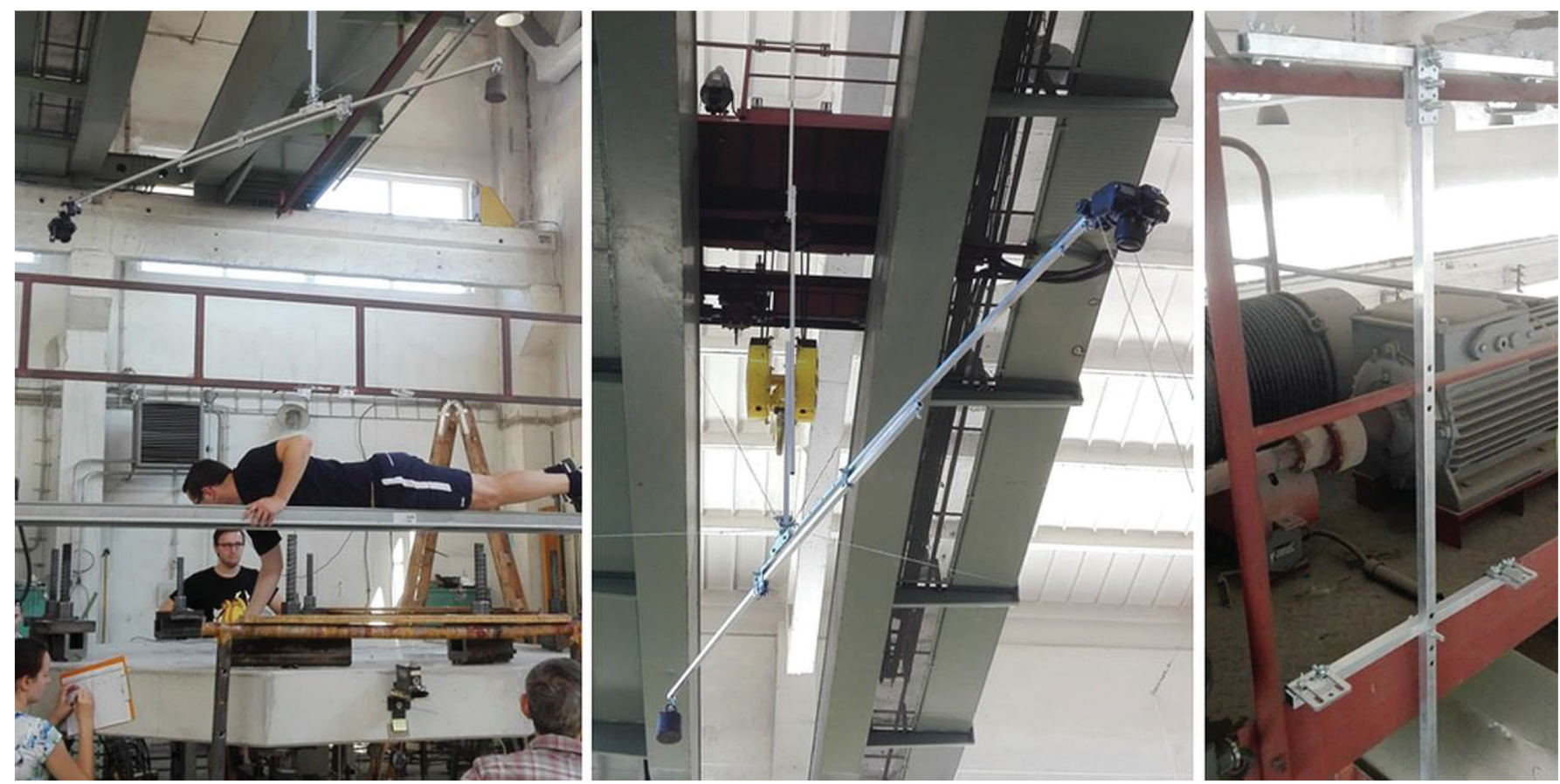

Fig. 2 Hanging mounting construction with camera above the experiment and its stabilisation on a crane.

mounted camera is gained by a $5-\mathrm{kg}$ counterweight on the opposite side of the arm. Thanks to the stabilisation of the camera system on the crane, the camera positions are independent of any obstacles on the floor, and the whole system can be moved to any place in the laboratory.

At this time the rotation of the arm is operated manually from the ground using a cord, but it may be possible to enhance the system to an automatic motor-driven system in the future. However, the system fastens up the process of shooting also in this basic version.

\subsection{Camera system}

The images were taken remotely using a Nikon D800E DSLR equipped by a Nikkor 35mm AF-S ED 1:1.8G lens (Tab. 1). Thanks to the stable rotation radius, the camera-to-object distance did not change too much; and therefore, the focus could be the same for all images and set up to manual right after the first automatic focus.

Tab. 1 Parameters and setup of the camera

\begin{tabular}{|l|l|l|l|}
\hline Camera & Nikon D800E & Lens & $\begin{array}{l}\text { Nikkor 35mm } \\
\text { AF-S ED 1:1.8G }\end{array}$ \\
\hline Sensor size & $36 \times 24 \mathrm{~mm}$ & Focal length & $35 \mathrm{~mm}$ \\
\hline Image size & $7360 \times 4912$ pixels & ISO & 400 \\
\hline Exposure time & $1 / 250 \mathrm{~s}$ & Aperture & $\mathrm{f} / 8$ \\
\hline Focus & manual & Flash & On \\
\hline
\end{tabular}

The average camera-to-object distance was $3 \mathrm{~m} .18$ images were taken at every load stage with a configuration that created a full circle around the specimen (Fig. 3).

\subsection{Points observed, scale and object coordinate system}

The points observed were signalized by Ringed Automatically Detected Coded targets (RAD) used by PhotoModeler software

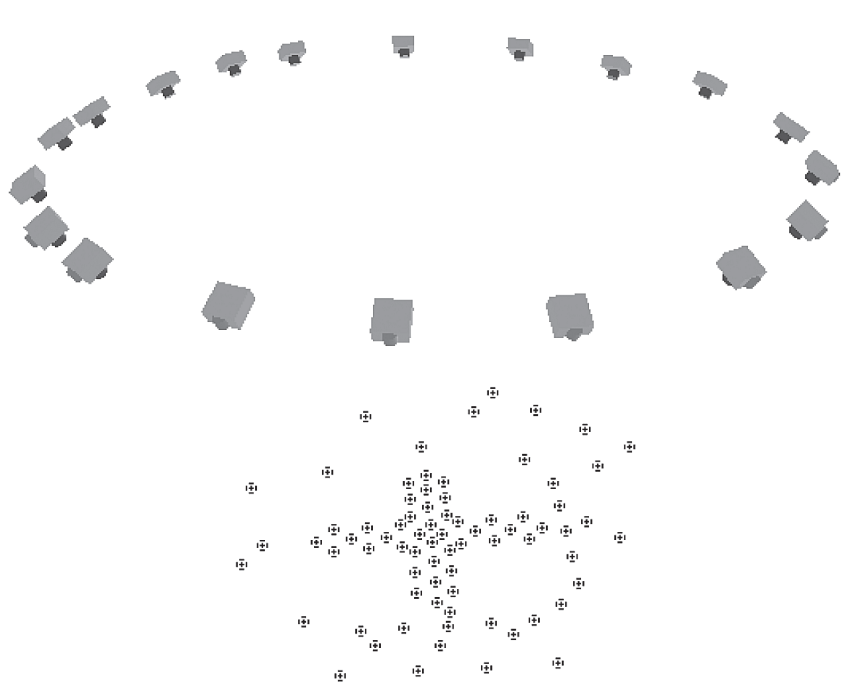

Fig. 3 Camera positions above the points observed.

(www.photomodeler.com, 2017). The main advantages of circular coded targets are the full automatic software measurement and an accuracy better than 0.1 pixel (Luhmann et al., 2006). The distribution of points over the specimens' surface was determined by the need for computation of strain in the main reinforcement directions (radial and tangential); thus the overall layout led to a cross-shaped structure with $200 \mathrm{~mm}$ spacing. These photogrammetric targets were glued on the specimens' surfaces close to special metal markers used for traditional contact measurement by a deformeter with an accuracy of $0.01 \mathrm{~mm}$ (Fig. 4). This enabled comparison of the results from the photogrammetric and deformeter measurements. The size of targets was $8 \mathrm{~mm}$ in diameter (black dot in the middle of the ringed code).

Additional targets were glued on 8 supporting steel rods to evaluate their stability during the loading.

The model's scale was determined by two special 1-m-long Dural scale bars with coded targets (Fig. 1). The scale bars were calibrated 


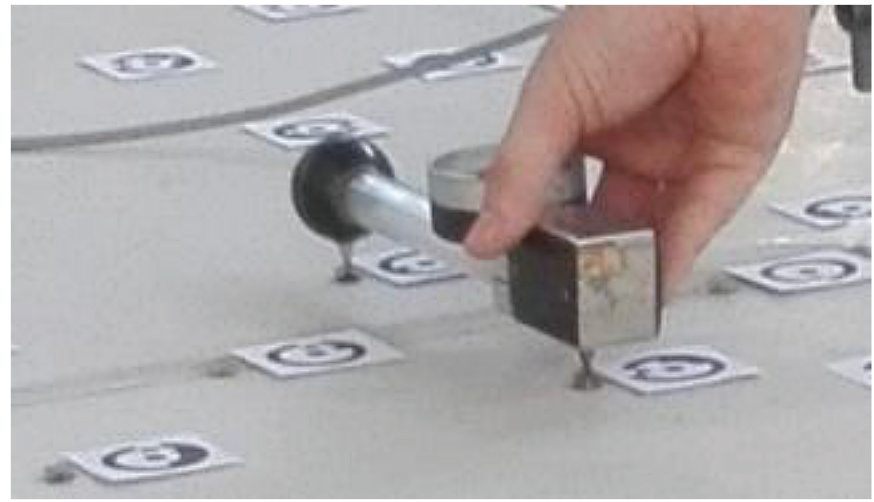

Fig. 4 Location of coded RAD targets and metal markers for determining the strain in the radial and tangential directions.

with a precision of $0.01 \mathrm{~mm}$ at temperature of $22{ }^{\circ} \mathrm{C}$ using a special calibration plate for a COMET LED structural light scanner. The coefficient of thermal expansion for the Dural material used reaches values of 22 to $23 \times 10^{-6} \mathrm{~K}^{-1}$. A change in material temperature of $1^{\circ} \mathrm{C}$ leads to a change of $0.02 \mathrm{~mm}$ for a $1 \mathrm{~m}$ length. The lengths of the scale bars used were corrected by these values; however, the changes in the $3 \mathrm{D}$ coordinates monitored were too small for the effect of the thermal expansion to manifest itself.

The object's coordinate system was defined using 8 targets and stabilized in two perpendicular directions on steel frames around the specimen. This points were considered stable during the load test; however, verification of their stability was done in the processing.

A total of 80 targets were placed on the observed object.

\subsection{Expected degree of accuracy}

The a priori degree of accuracy of convergent photogrammetry is possible to estimate using the following formula (Fraser, 1984):

$$
m_{p}=\frac{M_{s} \cdot m^{\prime} \cdot q}{\sqrt{k}}
$$

where $m_{p}$ is the spatial accuracy of the object point; $M_{s}$ represents the image scale number; $m^{\prime}$ is the accuracy of the image coordinates measurement; $q$ is a quality factor describing the camera's network configuration (0.5-1.2, smaller is better); and $k$ is the average number of photos taken from one camera position. Considering the circular shape of the targets and the automatic measurement of the image coordinates, we can assume a degree of accuracy of 0.1 pixel; thus the a priori degree of accuracy in the reference coordinate system reaches values of $0.02 \mathrm{~mm}$ (for $q=0.5$ ).

5 PHOTOGRAMMETRIC PROCESSING - BUNDLE ADJUSTMENT

The photogrammetric processing was performed using PhotoModeler software. A high degree of accuracy in photogrammetric processing is achievable only thanks to accurate calibration of the camera (Urban, 2008); therefore, on-the-job calibration was done on the object points, which led to maximum residuals under 0.2 pixel. The on-the-job calibration enables to simultaneously solve the 3D coordinates of the observed points and the interior orientation parameters of the camera

The scale and object coordinate system was defined in the processing of the $30 \mathrm{kN}$-load stage (the so-called own-weight stage). The difference in lengths between the two scale bars was under $0.01 \mathrm{~mm}$.
The XY plane was defined parallel to the object's surface; however, the rotation of this plane around the $\mathrm{Z}$ axis was irrelevant, because the aim was to compute only the relative changes in lengths observed in the $3 \mathrm{D}$ coordinate system and not the changes in the specific directions of the $\mathrm{X}$ or $\mathrm{Y}$ axes. The $+\mathrm{Z}$ axis was pointing upward, so it was possible to compare the changes in the photogrammetric $\mathrm{Z}$ coordinates and the deflection in the middle of the specimen measured by LVDT.

Then the $3 \mathrm{D}$ coordinates of the 8 points determining the reference frame were exported and served as control points for all the following load stages (3D conformal transformation) with no need of repeated measurement of the scale bars. We can estimate the accuracy of photogrammetric processing based on various criteria. One way of processing verification is to check the residuals on the points - the difference between the position of the measured point in the image and the position of the reprojection of the solved 3D point back into the image plane. Another way how to inspect the quality of the results is to compare them with the results from other methods of measurement. However, the differences of $0.01 \mathrm{~mm}$ between the lengths of two scale bars located perpendicularly to each other, serve as a good verification for a possible deformation of the network of the photogrammetric points.

The example of the statistics from the photogrammetric processing is in Tab. 2. The RMS values are computed from the residuals of all $3 \mathrm{D}$ points and their projections in the photogrammetric project.

Tab. 2 Statistics from the multi-image convergent photogrammetry during the $30 \mathrm{kN}$-load stage

\begin{tabular}{|l|l|}
\hline Intersections of rays per one point (average) & 14 \\
\hline Average number of points per photo & 59 \\
\hline Average intersection angle & $73^{\circ}$ \\
\hline Average camera-to-object distance & $3.0 \mathrm{~m}$ \\
\hline Max. residual & 0.10 pix \\
\hline Overall RMS Residual & 0.03 pixels \\
\hline Overall RMS in object coordinate system & $0.007 \mathrm{~mm}$ \\
\hline Precision of X/Y/Z coordinates (max.) & $0.007 / 0.006 / 0.017$ \\
\hline
\end{tabular}

A total of 12 load stages were evaluated, which, thanks to the configuration of similar camera positions in all the load stages, produced negligible differences in the statistical values. The signalisation of some points was negatively influenced by unwanted shadows and resulted in a higher RMS. Therefore, the unreliable measurements were deleted.

The overall residuals on the 8 control points used for the 3D conformal transformation into the reference coordinate system were no bigger than $0.02 \mathrm{~mm}$.

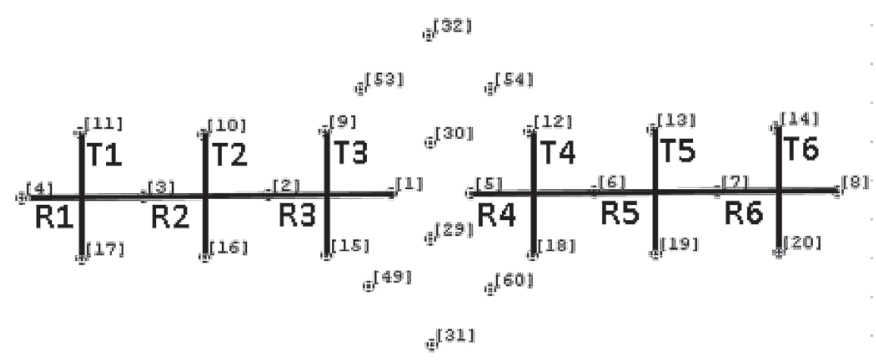

Fig. 5 Positions of lengths analysed in radial and tangential directions. 


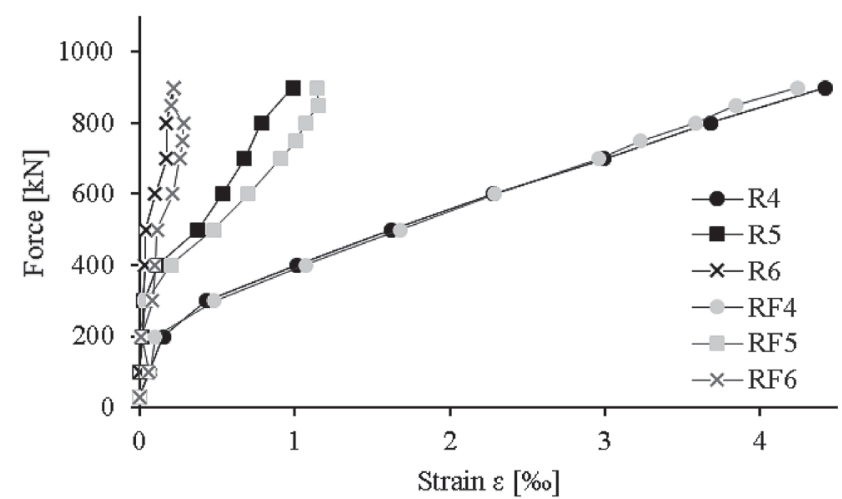

Fig. 6 Strain in radial direction ( $R$ - from deformeter, $R F-$ from photogrammetry).

\section{RESULTS}

\subsection{Strain}

The 3D coordinates of the points observed enabled the computation of the strain of the 200-mm lengths on the specimens' surface in the radial and tangential directions (Fig. 5). The comparison of strains obtained photogrammetrically and from direct measurements using a deformeter are shown in Figs. 6 and 7.

As shown in Figs. 6 and 7. the differences between the two methods are very small, but a numerical comparison would be more illustrative. The differences between the strain $\varepsilon[\%$ ] obtained from both methods are shown in Tabs. 3 and 4. The deformeter measurements were only carried out in 10 load stages, so only the comparable stages are shown.

Significant differences were only detected in the radial direction (R2 and R3 in Tab. 3); however, this can be easily explained: the points used by both methods for the strain computations were not identical points (just nearby points), and in some cases, the cracks

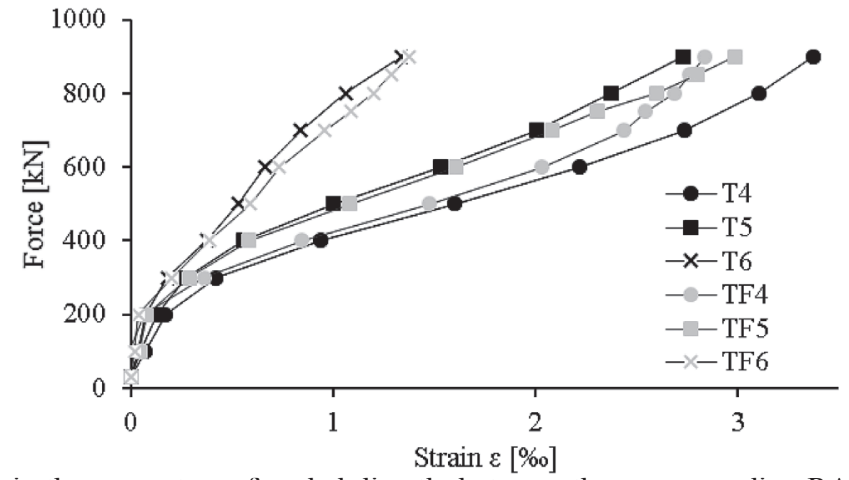

in the concrete surface led directly between the corresponding RAD Fig. 7 Strain in tangential direction ( $T$-from deformeter, $T F-$ from photogrammetry).

target and the metal marker, which produced the differences between the strains computed.

If we take into account the fact that the differences between the comparable strains reached an average value of $0.1 \%$, we deal with a value change of $0.02 \mathrm{~mm}$ for a $200 \mathrm{~mm}$ length. Such a degree of precision is sufficient for the needs of deformation measurement during load tests of construction elements.

The use of photogrammetry for this purpose also opens the question of safety during the loading. The direct contact measurement of relative deformations using a deformeter hanging from a metal board $0.5 \mathrm{~m}$ above a flat slab deformed by a massive force of nearly 1000 $\mathrm{kN}$ could be considered dangerous (Fig. 2, left).

\subsection{Vertical changes}

One of the many advantages of multi-photo convergent photogrammetry is the ability to evaluate the observed points in $3 \mathrm{D}$ space. There was a set of LVDTs installed on the flat slab; one of them in the

Tab. 3 Differences between strains in [\%o] in radial direction (deformeter - photogrammetry).

\begin{tabular}{|c|c|c|c|c|c|c|c|c|c|c|}
\hline Load stage $(\mathrm{kN})$ & 30 & 100 & 200 & 300 & 400 & 500 & 600 & 700 & 800 & 900 \\
\hline R1 & 0.00 & -0.05 & -0.02 & -0.06 & -0.09 & -0.07 & -0.02 & 0.04 & 0.10 & 0.16 \\
\hline R2 & 0.00 & -0.01 & -0.01 & -0.16 & -0.41 & -0.56 & -0.85 & -1.32 & -2.01 & -2.57 \\
\hline R3 & 0.00 & -0.01 & 0.02 & 0.03 & -0.04 & -0.02 & 0.13 & 0.50 & 1.22 & 1.85 \\
\hline R4 & 0.00 & 0.00 & 0.05 & -0.05 & -0.06 & -0.05 & -0.02 & 0.04 & 0.09 & 0.18 \\
\hline R5 & 0.00 & 0.00 & 0.02 & -0.01 & -0.08 & -0.10 & -0.16 & -0.23 & -0.29 & -0.15 \\
\hline R6 & 0.00 & -0.06 & 0.01 & -0.06 & -0.07 & -0.07 & -0.12 & -0.08 & -0.11 & 0.00 \\
\hline
\end{tabular}

Tab. 4 Differences between strains in tangential direction (deformeter - photogrammetry).

\begin{tabular}{|c|c|c|c|c|c|c|c|c|c|c|}
\hline Load stage $(\mathrm{kN})$ & 30 & 100 & 200 & 300 & 400 & 500 & 600 & 700 & 800 & 900 \\
\hline $\mathrm{T} 1$ & 0.00 & -0.01 & 0.00 & -0.07 & -0.10 & -0.13 & -0.12 & -0.15 & -0.15 & -0.10 \\
\hline $\mathrm{T} 2$ & 0.00 & -0.02 & 0.03 & -0.06 & -0.10 & -0.15 & -0.19 & -0.21 & -0.18 & -0.17 \\
\hline $\mathrm{T} 3$ & 0.00 & -0.03 & -0.02 & -0.13 & -0.21 & -0.18 & -0.18 & -0.13 & -0.09 & -0.03 \\
\hline T4 & 0.00 & 0.03 & 0.05 & -0.04 & -0.08 & -0.15 & -0.12 & -0.03 & 0.07 & 0.18 \\
\hline T5 & 0.00 & 0.00 & 0.05 & -0.02 & -0.03 & -0.09 & -0.08 & -0.07 & -0.23 & -0.26 \\
\hline T6 & 0.00 & 0.01 & 0.03 & -0.03 & -0.02 & -0.06 & -0.08 & -0.12 & -0.14 & -0.04 \\
\hline
\end{tabular}




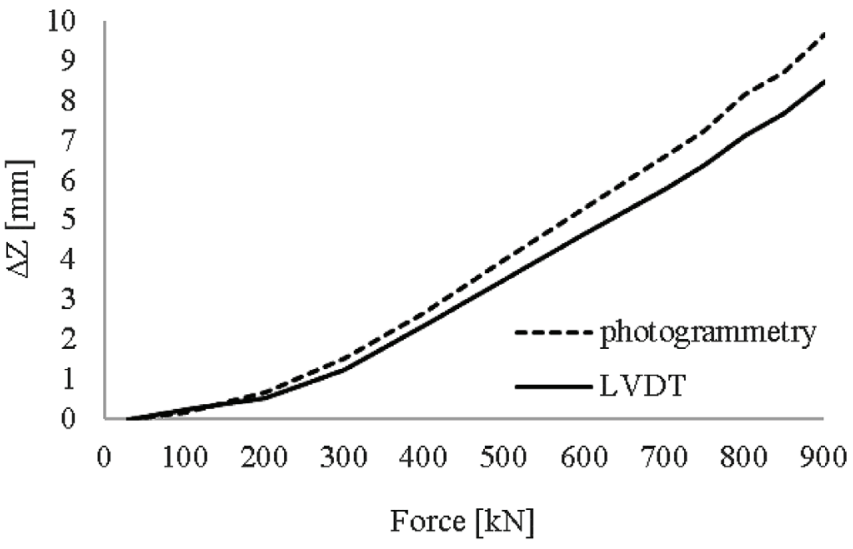

Fig. 8 Comparison of the deflection in the middle of the specimen determined by photogrammetry and by the LVDT.

center of the specimen was connected with a computer and produced detailed information about the deflection of the flat slab in the $\mathrm{Z}$ direction. From a photogrammetric point of view, there were 4 targets located $7 \mathrm{~cm}$ around the central LVDT; thus it was possible to compare the average changes of the $\mathrm{Z}$ coordinates of these 4 points with the results from the LVDT (Fig. 8).

There is a systematic effect visible on the changes determined in the $\mathrm{Z}$ coordinates in the previous chart. The maximum differences between the results from both methods were $1.15 \mathrm{~mm}$ by the end of the experiment. This can again be explained by the non-identical locations of the points observed.

The 8 RAD targets located on the supporting steel rods were used for the evaluation of the effect of the distribution of force over the specimen. It is clear from the chart in Fig. 9 that the slippage on the rods was different during the loading, specifically on the one with No. 21.

\section{CONCLUSION}

The results from the actual measurements demonstrate that multi-image convergent photogrammetry is an effective, accurate and suitable method for displacement measurements during load tests of construction elements, especially if optimal camera configuration is provided. It enables contactless control not only of the points on the object tested but also on the load-test construction around it. Thanks to this distribution of points, it can produce a complex image of the deformations of the object observed and, after a deep analysis, it can help adjust the loading structure by correcting any unreliable elements. It objectifies the whole measurement procedure.

The use of photogrammetry reduces the regular costs spend on disposable tensometers, enhances the density of measurements, excludes the need for the contact measurement of a strain using a deformeter; and speeds up the whole measurement process during the load test.

However, to achieve the high degree of precision and reliability of photogrammetric measurements, it is necessary to pay special attention to the stabilization of the reference coordinate system, the definition of the scale, the signalization of the points observed, the configuration of the cameras, and the processing parameters.

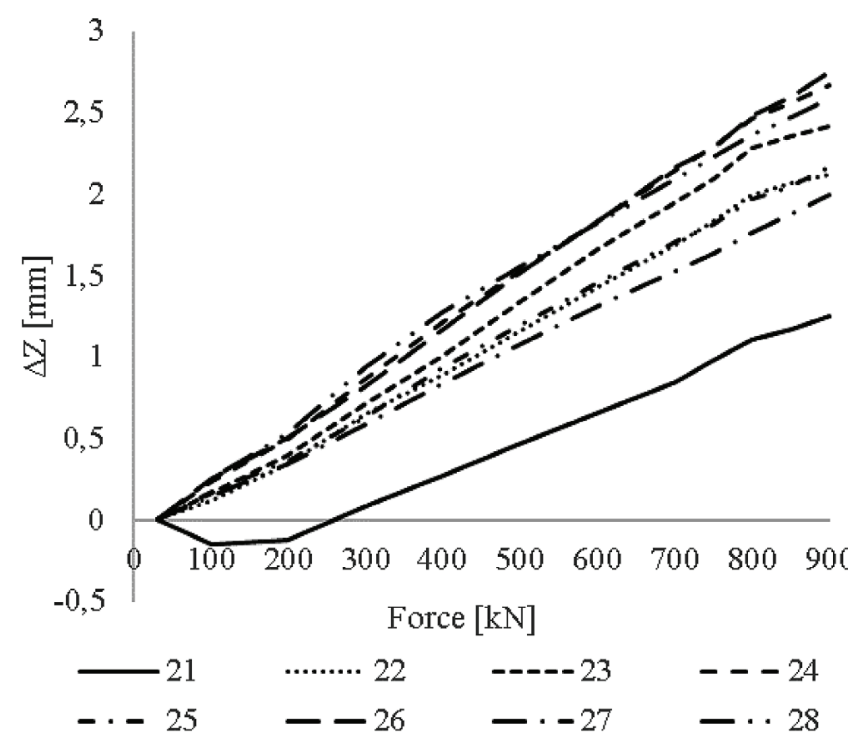

Fig. 9 Changes in $Z$ coordinates of the 8 points located on the supporting steel rods.

\section{Acknowledgements}

This article is the result of the implementation of the KEGA project No. 037STU-4/2016 "Modernization and Development of Technological Skills in teaching Surveying and Photogrammetry".

This work was supported by the Scientific Grant Agency of the Ministry of Education, Science, Research and Sport of the Slovak Republic and the Slovak Academy of Sciences No. 1/0810/16. 


\section{REFERENCES}

Fraser, C. S. (1984) Network design optimization in non-topographic photogrammetry, IA PRS, Vol. XXV, part A5, pp. 296-308, Rio de Janeiro, 1984.

Fraser, C. S. - Riedel, B. (2000) Monitoring the thermal deformation of steel beams via vision metrology, ISPRS Journal of Photogrammetry \& Remote Sensing 55. 268-276, https://doi. org/10.1016/S0924-2716(00)00024-1

Koschitzki, R. - Schacht, G. - Schneider, D. - Marx, S. - Maas, H.-G. (2011) Integration of photogrammetry and acoustic emission analysis for assessing concrete structures during loading tests, SPIE 8085, Videometrics, Range Imaging, and Applications XI, 80850I (21 June 2011); doi: 10.1117/12.889558

Lee, T. K. - Al-Mahaidi, R. (2008) An experimental investigation on shear behaviour of RC T-beams strengthened with CFRP with photogrammetry. Composite Structures 82(2), pp. 185-193.

Lucieer, A. - de Jong, S. M. - Turner, D. (2013) Mapping landslide displacements using Structure from Motion (SfM) and image correlation of multi-temporal UAV photography. Progress in Physical Geography. Vol 38, No. 1, pp. 97 - 116. First published date: Dec. 24, 2013.

Luhmann, T. - Robson, S. - Kyle, S. - Harley, I. (2006) CloseRange Photogrammetry. Whittles Publishing, Dunbeath, Scotland, UK. pp. 374 - 376. ISBN 1-870325-50-8.

Luhmann, T. (2010) Close range photogrammetry for industrial applications. ISPRS Journal of Photogrammetry and Remote Sensing, 65 (2010), pp. 558-569. doi:10.1016/j.isprsjprs.2010.06.003.

Majtánová, L. - Hanzel, J. - Halvoník, J. (2016) The experimental verification of maximum punching shear resistance. Interdisciplinarity in theory and practice, NR.: 10. ISSN $2344-2409$.

Parian, J. - Gruen, A. - Cozzani, A. (2008) Monitoring of the reflectors of ESA's Planck telescope by close-range photogrammetry. Journal of Applied Geodesy jag, 1(3), pp. 137-145.

Shortis, M. R. - Robson, S. - Jones, T. W. - Goad, W. K. - Lunsford, C. B. (2016) Photogrammetric tracking of aerodynamic surfaces and aerospace models at NASA Langley Research Center, ISPRS Ann. Photogramm. Remote Sens. Spatial Inf. Sci., III-5, 27-34, https://doi.org/10.5194/isprs-annals-III-5-27-2016, 2016.
Šedina, J. - Pavelka, K. (2016) Precise Photogrammetric Methods for Deformation Measurements. In.: Interdisciplinarity in Theory and Practice. 2016, 2016(10), pp. 285-290. ISSN 2344-2409. Available at: http://www.itpb.eu/index.php/ct-menu-item-3/14engineering/347-10-cislo-53-clanok

Šedina, J. - Pavelka, K. - Housarová, E. (2016) Using of photogrammetric methods for deformation measurements and shape analysis. In: Advances and Trends in Engineering Sciences and Technologies II: Proceedings of the 2nd International Conference on Engineering Sciences and Technologies, 29 June - 1 July 2016, High Tatras Mountains, Tatranské Matliare, Slovak Republic. 2nd International Conference on Engineering Sciences and Technologies. Tatranské Matliare, 29.06.2016 - 01.07.2016. Boca Raton: CRC Press. 2016, s. 841-846. ISBN 9781138032248. Available at: http://www.crenetbase.com/doi/abs/10.1201/9781315393827142 .

Urban, R. (2008) Lens Distortion Influence Suppression. Geodézia, kartografia a geografické informačné systémy 2008 [CD-ROM], Košice: Technical University BERG Faculty, 2008, pp. 1-10. ISBN 978-80-553-0079-5.

Urban, R. - Braun, J. - Štroner, M. (2015) Precise deformation measurement of prestressed concrete beam during a strain test using the combination of intersection photogrammetry and micro-network measurement. Proceedings of SPIE: The International Society for Optical Engineering, 2015, 9528, pp. ISSN $0277-$ $786 \mathrm{X}$.

Valença, J. - Júlio, E. - and Araújo, H. (2012) Application of photogrammetry to structural assessment. Experimental Techniques, 36(5), 71-81.

www.photomodeler.com (2017) PhotoModeler Coded Targets \& Automation. Available at: http://www.photomodeler.com/products/pm_automation.html 